\title{
Determinação da tensão de aderência do bambu-concreto
}

\author{
Ligia P. Mesquita ${ }^{1}$, Cleber J. Czarnieski ${ }^{1}$, Antônio C. Braga Filho², Fábio L. Willrich', \\ Humberto C. Lima Júnior ${ }^{1} \&$ Normando P. Barbosa ${ }^{2}$
}

\begin{abstract}
RESUMO
Apresenta-se e se discute, neste trabalho, o estudo da aderência entre o bambu e o concreto; através de dois estudos baseados em uma programação estatística de experimento, em que no primeiro se investigaram as influências da dimensão da seção transversal das varetas de bambu e da resistência do concreto na aderência bambu-concreto e, no segundo, avaliou-se o efeito da colocação de pinos artificiais nas varetas de bambu. Em cada estudo realizaram-se 10 réplicas para cada combinação de fatores, resultando no total de 159 ensaios de arrancamento. Curvas tensão de aderência versus deslocamento relativo bambu-concreto, são apresentadas e discutidas, e a tensão de aderência de cálculo é calculada e comparada com os valores sugeridos por normas internacionais para barras lisas de aço. Constatou-se, na primeira fase da investigação, que apenas a resistência do concreto influencia na aderência bambu-concreto e que esta tensão é apenas $20 \%$ inferior que a do aço liso-concreto; já na segunda fase verificou-se que os pinos de bambu e de aço elevam a capacidade de transferência de tensões bambu-concreto, de forma significativa.
\end{abstract}

Palavras-chave: dimensões da seção transversal, resistência à compressão do concreto, ancoragem mecânica

\section{Determination of the bamboo-concrete bond stress}

\begin{abstract}
This paper presents and discusses a study about the bamboo-concrete bond stress. Based on a statistical design of experiment, the investigation was divided in two steps: the first one, where the effects of the concrete compressive strength and the dimensions of the bamboo-splint cross-section were investigated; and the second, where the effect of artificial pins studding in the bamboo splints were evaluated. In both steps, ten replicates for each factor combination were done, resulting in 159 push-out tests. Bond stress versus relative displacement curves were presented and discussed. In addition, the design bond stresses of bamboo-concrete were calculated and their values were compared with those specified by International Building Codes for smooth steel and concrete. In the first step, it was observed that only the concrete compressive strength influences the bamboo-concrete bond stress and that, this stress is only $20 \%$ inferior to the smooth steel-concrete bond stress. In the second step, it was verified that bamboo and steel pins increased the transfer stress capacity between the concrete and bamboo.
\end{abstract}

Key words: cross section dimensions, compressive concrete strength, mechanic bond

1 UNIOESTE. Rua Universitária, 2069, CEP 85814-110, Cascavel, PR. Fone: (45) 3220-3221. E-mail: mesquita@unioeste.br; czarnieski@unioeste.br; flwillich@unioeste.br; humbertolima@ufpe.br

2 UFPB. Cidade Universitária, CEP 58059-900, João Pessoa, PB. Fone: (83) 3246-2669. E-mail: ant.filho@bol.com.br; nperazzo@|sr.ct.ufpb.br 


\section{INTRODUÇÃO}

A concepção básica de uma estrutura de concreto armado consiste na capacidade do concreto de resistir aos esforços de compressão, e o reforço, aos esforços de tração. Para que tal sistema seja eficiente e responda adequadamente às solicitações da estrutura, deve haver transferência de forças entre o concreto e a armadura (Macgregor, 1997). A aderência entre o concreto e o reforço é responsável por essa transferência, quando da fissuração do primeiro. Quando eficiente, a aderência garante que esses dois materiais trabalhem de forma unificada, garantindo também a capacidade do concreto de continuar a resistir aos esforços após a ocorrência da sua fissuração (Park \& Paulay, 1975).

O bambu é um material que possui propriedades mecânicas compatíveis às dos materiais utilizados em estruturas de concreto armado (Lima Jr. et al., 2000); por este motivo, vem sendo estudada a possibilidade da utilização desse material como reforço em estruturas de concreto armado (Geymayer \& Cox, 1970). Apesar do descrito, verifica-se que a utilização do bambu com esta finalidade tem sido dificultada pela baixa aderência desenvolvida entre este material e o concreto (Kurian \& Kalam, 1977). Segundo Ghavami (1995) e Lopes et al. (2002), o bambu, quando utilizado como reforço no concreto, absorve a água da mistura, aumentando de volume e voltando às dimensões originais, após secagem; isto faz com que a aderência entre os dois materiais seja prejudicada. Apesar desse fato, não foram encontrados, na literatura nacional nem na internacional, trabalhos que quantifiquem a variação da taxa volumétrica do bambu imerso no concreto nem, tampouco, o valor da perda de aderência devido a esse efeito higroscópico.

O problema da baixa aderência bambu-concreto vem sendo estudado por diversos pesquisadores (Ghavami \& Hombeck, 1981; Beraldo, 1987; Ferrão \& Freire, 1995; Ghavami, 1995; Lima Jr. et al., 1996; Lopes et al., 2002; e Da Rosa, 2002). Apesar disso, constata-se que nesses trabalhos as metodologias experimentais utilizadas para o ensaio de arrancamento push-out test não se mostraram adequadas, uma vez que os deslocamentos medidos apresentaram interferência de deslocamentos parasitas, provenientes das acomodações e deformações da máquina de ensaio e de irregularidades da superfície de contato entre o bloco de concreto e os pratos das prensas; além disso, observa-se que os tratamentos estudados nesses trabalhos para melhorar o mecanismo de aderência bambuconcreto, basicamente consistiam na aplicação, por meio de pintura, de resinas impermeabilizantes à superfície do bambu; entretanto, a grande maioria das resinas estudadas possuía baixa resistência ao cisalhamento e funcionava como lubrificante entre o bambu e o concreto, ou era materiais termoplásticos que se fluidificam com a elevação da temperatura, como é o caso do asfalto. Com base nisto, nota-se que, em sua grande totalidade, os resultados obtidos foram piores que aqueles com o bambu sem tratamento; em outros casos, as resinas utilizadas foram epoxídicas, casos em que se observam elevações acentuadas na tensão de aderência bambuconcreto, porém o custo financeiro dessas resinas é elevado e torna a utilização do bambu mais cara que a do aço.
Com base no exposto, verifica-se que a questão da aderência bambu-concreto é complexa e que se fazem necessários maiores estudos para tentar solucionar as questões levantadas. Os resultados apresentados neste artigo fazem parte de um programa de pesquisa mais amplo, que visa estudar estruturas de concreto reforçadas com bambu e, atualmente, vem sendo desenvolvido, em parceria, por três instituições de pesquisa: pela Universidade Estadual do Oeste do Paraná, pelo Laboratório de Tecnologia do Concreto de Itaipu e pela Universidade Federal da Paraíba. Este artigo apresenta os resultados de um estudo que visou eliminar os problemas com deslocamentos parasitas no ensaio de arrancamento e estudar a aderência bambu-concreto, verificando a influência da resistência do concreto, das dimensões da seção transversal das varetas de bambu e do aumento da aderência mecânica bambu-concreto, por meio de cravação de pinos nas varetas de bambu.

\section{MATERIAL E MÉTODOS}

\section{Metodologia de avaliação da aderência bambu concreto}

Diversos pesquisadores sugerem que a aderência reforçoconcreto é composta por três parcelas: pela aderência por adesão, por atrito e mecânica (FIB, 1999). Quando uma estrutura de concreto armado é solicitada por forças de pequena magnitude, desenvolve-se a aderência por adesão (estágio 1); essas forças são resultado tanto da aderência química entre os materiais, produzida na interface reforço-concreto durante as reações de hidratação do cimento, quanto da aderência física provocada por efeitos de capilaridade, a qual está diretamente ligada à deformação elástica da camada cimentícia em torno da barra componente da armadura. A aderência por adesão se rompe após um pequeno deslocamento relativo e, a partir de então, sua contribuição é praticamente nula. No caso de reforços com superfície lisa, após a ruptura da aderência por adesão ocorre a ativação da aderência por atrito (estágio 2), cuja parcela está diretamente relacionada ao coeficiente de atrito entre as superfícies e a força de compressão perpendicular ao plano de contato, proveniente da retração do concreto, da irregularidade do plano de deslizamento e do efeito de cunha das partículas do concreto; neste caso, o plano de deslizamento coincide com a superfície de contato reforço-concreto e, então, por causa da baixa rugosidade do plano de atrito, observa-se que o efeito de cunha das partículas do concreto é pequeno e, conseqüentemente, a tensão de aderência diminui com o aumento do deslizamento.

Para reforços com superfícies irregulares ou com variação da seção transversal, depois de rompida a aderência por adesão são ativadas, concomitantemente, as parcelas da aderência por atrito e mecânica (estágios 2 e 3). Vê-se, neste caso, que a superfície de deslizamento não é regular nem coincide com a superfície do reforço; assim, como o efeito de cunha das partículas do concreto e o efeito de cunha causado pela irregularidade da geometria da barra são elevados, o esforço normal é bem superior ao das barras lisas e 
a tensão de atrito se eleva com o deslizamento relativo da barra. Em adição, verifica-se que a parcela relativa à aderência mecânica é função do engrenamento mecânico entre as irregularidades da superfície do reforço e o concreto. As irregularidades do reforço funcionam como consolos que tentam cortar a pasta do concreto. Segundo Leonhardt (1977) esta parcela é a mais efetiva e confiável da aderência e é imprescindível para que se possa utilizar toda a capacidade resistente de reforços com elevada resistência à tração. Na Figura 1 apresentam-se, esquematicamente, as curvas tensão de aderência versus deslocamento relativo para os aços de construção e o concreto, podendo-se observar os três estágios de aderência para os aços com superfícies nervuradas, e os dois estágios para os aços com superfície lisa. Devido a superfície lisa do bambu e a partir da análise dos diagramas apresentados na Figura 1, espera-se que os diagramas de arrancamento bambu-concreto apresentem o mesmo comportamento daquele indicado pelos aços com superfícies lisas.

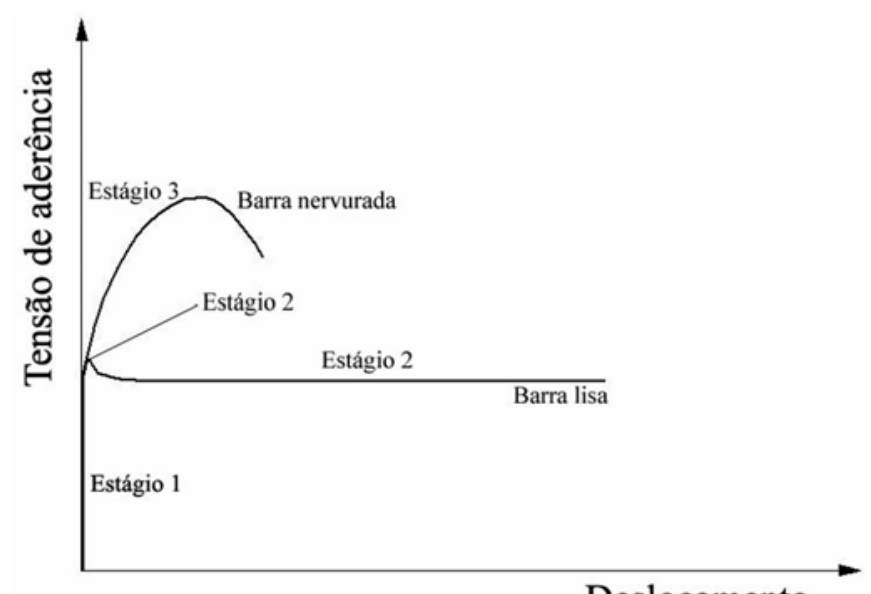

Deslocamento

Figura 1. Curvas esquemáticas tensão de aderência versus deslocamento e estágios da aderência aço-concreto (adaptadas de FIB, 1999)

Segundo RILEM-FIP-CEB (1973), a medição da variação das tensões ao longo do comprimento deve ser avaliada por meio de um valor médio calculado com base na Eq. 1:

$$
\tau_{\mathrm{bm}}=\frac{\mathrm{F}_{\mathrm{arr}}}{\mathrm{u} \cdot \mathrm{l}_{\mathrm{b}}}
$$

na qual $\mathrm{F}_{\text {arr }}$ é a força necessária para arrancar a vareta da massa de concreto, u é o perímetro de contato entre o reforço e o concreto e $l_{b}$ é o comprimento da barra em contato com o concreto. Em razão da grande dispersão dos valores das forças obtidas nos ensaios de arrancamento, RILEN-FIP-CEB (1973) sugere que a força de arrancamento $\mathrm{F}_{\text {arr }}$ seja definida como a força correspondente ao deslocamento de $0,1 \mathrm{~mm}$.

O Eurocode (1992) estabelece um coeficiente de 2,15 para o cálculo da tensão de aderência de cálculo a partir da tensão de aderência característica para os aços de construção e, ainda, que a tensão de aderência de cálculo para o caso de barras de aço lisas e nervuradas, deve ser calculada segundo as Eqs. 2 e 3, respectivamente:

$$
\begin{gathered}
\mathrm{f}_{\mathrm{bd}}=\frac{0,36 \cdot \gamma_{\mathrm{m}} \cdot \sqrt{\mathrm{f}_{\mathrm{ck}}}}{\gamma_{\mathrm{c}}} \\
\mathrm{f}_{\mathrm{bd}}=\frac{0,472 \cdot \gamma_{\mathrm{m}} \cdot \sqrt[3]{\mathrm{f}_{\mathrm{ck}}^{2}}}{\gamma_{\mathrm{c}}}
\end{gathered}
$$

nas quais $\mathrm{f}_{\mathrm{ck}}$ é a resistência característica do concreto, $\gamma_{\mathrm{c}}$ é um coeficiente de minoração da resistência à compressão do concreto e $\gamma_{m}$ é um coeficiente de minoração global. Os valores de $\gamma_{c}$ e $\gamma_{m}$ são 1,5 e 0,7 , respectivamente. Observa-se que a aplicação desses dois coeficientes de minoração gera o valor de 2,15, já citado.

\section{Materiais}

O agregado miúdo utilizado foi areia quartzosa, com módulo de finura de 2,11, diâmetro máximo de 2,4 mm e massa específica aparente de 1,62 $\mathrm{kg} \mathrm{dm}^{-3}$ (ABNT 248, 2003 e ABNT 52, 2003). Utilizou-se agregado graúdo de origem basáltica com módulo de finura de 6,8 , diâmetro máximo de $19 \mathrm{~mm}$ e massa específica aparente de $1,92 \mathrm{~kg} \mathrm{dm}^{-3}$ (ABNT 248, 2003 e ABNT 53, 2003). O cimento utilizado foi o Portland branco, CPB-40, que apresentava finura Blaine de $426 \mathrm{~m}^{2} \mathrm{~kg}^{-1}$.

As porcentagens dos materiais foram definidas a partir de uma curva experimental de dosagem (Helene \& Terzian, 1995), para a qual se adotou teor de argamassa de 50\%, uma relação água/materiais secos de $8,8 \%$ e abatimento no cone de Abrams de $15 \mathrm{~cm} \pm 2 \mathrm{~cm}$. As resistências dos concretos foram avaliadas aos sete dias, por meio de ensaio de corposde-prova cilíndricos 15 × $30 \mathrm{~cm}$, vibrados mecanicamente. $\mathrm{O}$ ensaio dos corpos-de-prova seguiu as prescrições da norma ABNT 5739 (1994). Estabeleceram-se três resistênciasbase para os concretos a serem estudados na fase 1 da investigação: 15,25 e $35 \mathrm{MPa}$. As características dos concretos utilizados são apresentadas na Tabela 1.

Tabela 1. Propriedades do concreto

\begin{tabular}{ccccccc}
\hline $\begin{array}{c}\text { Resistência } \\
(\mathbf{M P a})\end{array}$ & Traço & $\begin{array}{c}\text { Slump } \\
(\mathbf{m m})\end{array}$ & $\mathbf{a} / \mathbf{c}$ & $\begin{array}{c}\boldsymbol{\gamma}_{\mathbf{c}} \\
\left(\mathbf{k g ~ m}^{-3}\right)\end{array}$ & $\begin{array}{c}\mathbf{f}_{\mathrm{cj}}-\mathbf{s} \\
(\mathbf{M P a})\end{array}$ & $\begin{array}{c}\mathbf{f}_{\text {ck }} \\
(\mathbf{M P a})\end{array}$ \\
15 & $1: 3,2: 4,2$ & 16 & 0.68 & 2409,5 & $16,8-3,7$ & 10,8 \\
25 & $1: 2,4: 3,4$ & 14 & 0,58 & 2440,2 & $25,2-3,4$ & 19,6 \\
35 & $1: 1,8: 2,8$ & 16 & 0,50 & 2443,9 & $39,6-4,7$ & 31,8 \\
\hline
\end{tabular}

Nota: a/c é a relacão água cimento-1 $\gamma_{c}$ é a massa específica do concreto, $f_{c} \cdot$ é a resistência média dos corpos-de-prova, $\mathrm{f}_{\mathrm{ck}} \mathrm{e}$ a resistência característica do concreto, $\mathrm{s}$ é o desvio-padrão da amostra

O bambu utilizado foi da espécie Dendrocalamus giganteus, cujos colmos foram cortados com idade entre dois e três anos e deixados para secar à sombra, em temperatura ambiente, pelo período de três meses. Estes apresentavam comprimento médio de $20 \mathrm{~m}$ e foram divididos em três trechos de igual comprimento, denominados: basal, intermediário e topo. Apenas os trechos basais e intermediários foram utilizados. As propriedades mecânicas do bambu utilizado são apresentadas na Tabela 2. 
Tabela 2. Propriedades mecânicas do bambu Dendrocalamus giganteus (Lima Jr. et al., 2000)

\begin{tabular}{ccccccc}
\hline Região & $\begin{array}{c}\mathrm{f}_{\mathrm{tb}} \\
(\mathrm{MPa})\end{array}$ & $\begin{array}{c}\mathrm{E}_{\mathrm{t}} \\
(\mathrm{GPa})\end{array}$ & $\begin{array}{c}\mathrm{f}_{\mathrm{cb}} \\
(\mathrm{MPa})\end{array}$ & $\begin{array}{c}\mathrm{E}_{\mathrm{c}} \\
(\mathrm{GPa})\end{array}$ & $\boldsymbol{v}$ & $\begin{array}{c}\tau_{\mathbf{b}} \\
(\mathrm{MPa})\end{array}$ \\
Nodal & 97 & 13 & 58 & 19 & - & - \\
Internodal & 277 & 23 & 58 & 22 & 0,24 & 7,8 \\
\hline
\end{tabular}

Nota: $\mathrm{f}_{\mathrm{tb}}$ é a resistência à tração, $\mathrm{E}_{\mathrm{t}} \mathrm{e}$ o modulo de elasticidade na tração, $\mathrm{f}_{\mathrm{cb}} \mathrm{e}$ a resistência à compressão, vé 0 coeficiente de Poisson e $\tau_{b}$ é a resistência ao cisalhamento paralelo às fibras do bambu.

Utilizaram-se barras de aço nervuradas com diâmetro de $10 \mathrm{~mm}$, tensão de escoamento de $628 \mathrm{MPa}$ e módulo de elasticidade de $219 \mathrm{GPa}$, para ensaio de arrancamento, a título de comparação com o bambu.

\section{Variáveis estudadas e preparação dos corpos-de-prova da $1^{\text {a }}$ fase da investigação}

O procedimento da escolha das variáveis e de seus níveis de estudo seguiu uma programação fatorial de experimento (Montgomery, 1984). Duas variáveis foram selecionadas para análise nesta fase: as dimensões das seções transversais das varetas de bambu $\left(\mathrm{X}_{1}\right)$ e a resistência do concreto $\left(\mathrm{X}_{2}\right)$. Utilizaram-se três níveis de estudo para as duas variáveis: varetas de bambu, com dimensões das seções transversais de $1 \times 1,1 \times 1,5$ e $1 \times 2 \mathrm{~cm}$, e resistências médias à compressão do concreto de 15,25 e $35 \mathrm{MPa}$. Para cada combinação de variável foram preparadas dez réplicas, resultando em um programa fatorial de $3 \times 3 \times 10=90$ corpos-de-prova.

Os corpos-de-prova consistiam de varetas de bambu imersas em blocos cilíndricos de concreto com dimensões de $15 \times 30 \mathrm{~cm}$. As varetas foram cortadas da região inter-nodal dos colmos. Após o corte, essas foram limpas e suas dimensões medidas com paquímetro, apresentando seção transversal com espessuras e larguras médias de 8,8 x 10,0, 9,6 x 13,8 e 10,7 x 19,3 mm, respectivamente, e comprimento de $50 \mathrm{~cm}$; em seguida, o trecho de $30 \mathrm{~cm}$ a ser imerso nos blocos de concreto foi dividido em três regiões de igual comprimento com $10 \mathrm{~cm}$ cada uma. A avaliação da aderência foi realizada apenas nos $10 \mathrm{~cm}$ centrais (Figura 2); nas outras duas regiões, a aderência foi anulada por meio da colocação de graxa e de camadas sucessivas de papel. Objetivando-se avaliar a eficiência da técnica utilizada para anular a aderência bambu-concreto nas extremidades das varetas, ensaiaram-se 6 corpos-de-prova nos quais os $30 \mathrm{~cm}$ das varetas imersos no concreto receberam este tratamento. As varetas utilizadas nesses corpos-de-prova apresentavam seção transversal com espessuras e larguras médias de 10,1 x 9,4 mm e foram preparados dois corpos-de-prova para cada resistência à compressão do concreto. Finalmente, ensaiaram-se 9 corpos-deprova de arrancamento com barras de aço CA - 50 de $10 \mathrm{~mm}$ de diâmetro, sendo 3 corpos-de-prova para cada nível de resistência à compressão do concreto. A metodologia utilizada para o preparo dos corpos-de-prova com barras de aço foi a mesma empregada para aqueles com varetas de bambu.

Os corpos-de-prova foram moldados em formas metálicas e o concreto vibrado por meio de vibrador de agulha. A concretagem dos 99 corpos-de-prova foi dividida em nove betonadas; de cada betonada, moldaram-se três corpos-deprova cilíndricos 15 × $30 \mathrm{~cm}$ para avaliação da resistência
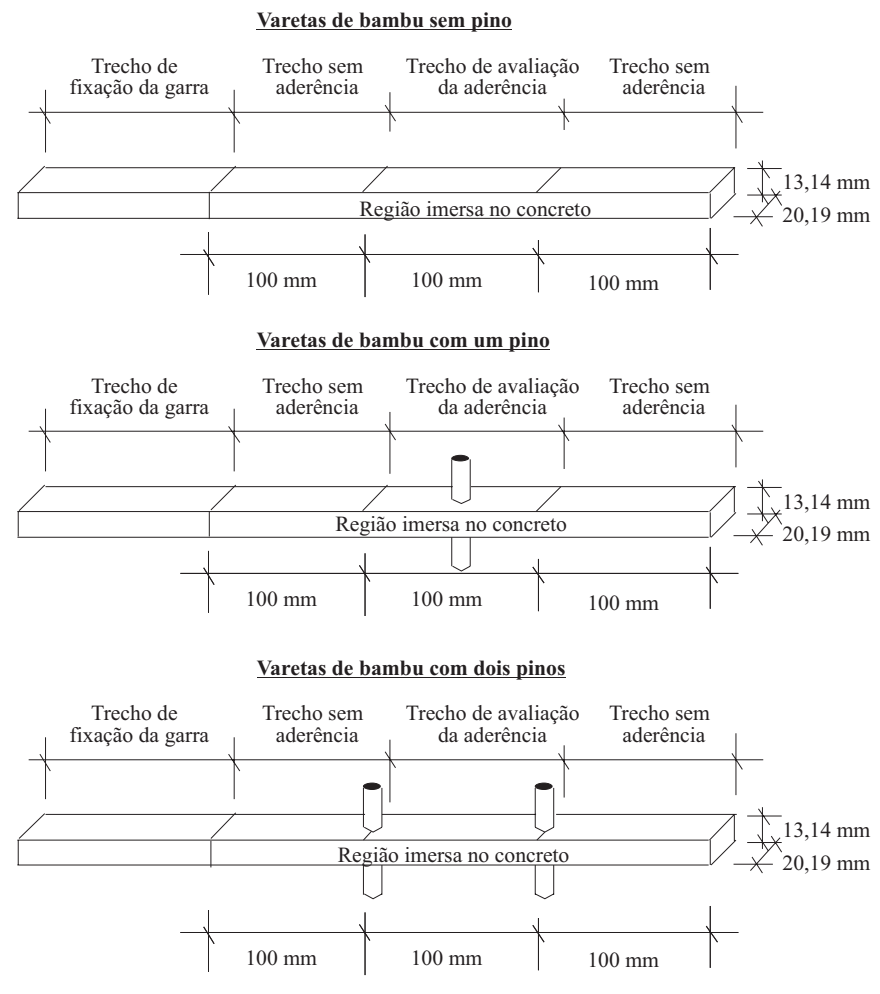

Figura 2. Característica dos corpos-de-prova

média à compressão do concreto, cujos valores foram apresentados na Tabela 1. Durante a concretagem, discos de madeira com $15 \mathrm{~cm}$ de diâmetro e $1 \mathrm{~cm}$ de espessura, furados no centro, foram dispostos nas extremidades dos moldes, objetivando a centralização das hastes de bambu em relação à massa de concreto. Após a concretagem, os corpos-de-prova foram deixados nas formas pelo período de $24 \mathrm{~h}$; depois, efetuou-se o desforma e os corpos-de-prova foram envoltos em lona plástica onde permaneceram por mais 7 dias, até serem ensaiados.

Os corpos-de-prova foram nomeados segundo as larguras das varetas de bambu e a resistência do concreto; assim, as letras do nome CPXY correspondem a: CP corpo-de-prova; $\mathrm{X}$, à largura das varetas e $\mathrm{Y}$ à resistência do concreto. Deste modo, o CP1025 se refere aos corpos-de-prova com varetas de $10 \mathrm{~mm}$ de largura e concreto com resistência à compressão de $25 \mathrm{MPa}$.

\section{Variáveis estudadas e preparação dos corpos-de-prova da $2^{a}$ fase da investigação}

Na segunda fase da investigação foi estudada e quantificada a parcela da aderência mecânica gerada por pinos artificiais cravados nas varetas de bambu. Duas variáveis foram selecionadas para análise: o tipo do pino (pino de aço e pino de bambu) e o número de pinos utilizados (um e dois pinos). Para cada combinação de variáveis foram preparadas dez réplicas. Em adição, ensaiaram-se dez corpos-de-prova com um pino de aço e dez com um pino de bambu, sem aderência por adesão.

A preparação e as características dos corpos-de-prova foram iguais àquelas da $1^{\text {a }}$ fase da investigação. Nesta, utilizaram-se varetas com seção transversal retangular com 
espessura e largura médias de 13,14 e 20,19 mm, respectivamente, e concreto com resistência média à compressão de $25 \mathrm{MPa}$. No trecho dos $10 \mathrm{~cm}$ das varetas, foram feitos furos de $8 \mathrm{~mm}$ de diâmetro para cravação dos pinos. Os pinos de aço e de bambu possuíam diâmetro de $8 \mathrm{~mm}$ e comprimento de $50 \mathrm{~mm}$. Objetivando-se quantificar apenas a parcela da aderência mecânica gerada pelos pinos, foram feitos também corpos-de-prova com pino e sem aderência, nas quais se seguiu o mesmo procedimento anteriormente descrito; contudo, a aderência por adesão nos $10 \mathrm{~cm}$ centrais das varetas de bambu foi anulada por meio da colocação de graxa e de camadas sucessivas de papel. Na Figura 2 apresentam-se detalhes das hastes de bambu.

Os corpos-de-prova da $2^{\mathrm{a}}$ fase foram nomeados de acordo com as letras iniciais das variáveis estudadas. Deste modo, os corpos-de-prova com um e dois pinos de aço e com aderência na região central das varetas, foram nomeados de 1PACA e 2PACA, respectivamente; os com um e dois pinos de bambu e com aderência na região central das varetas, foram nomeados de 1PBCA e 2PBCA, respectivamente, com um pino de aço e sem aderência na região central das varetas 1PASA e, finalmente, com um pino de bambu e sem aderência na região central das varetas de 1PBSA.

\section{Ensaio e instrumentação}

Os corpos-de-prova foram ensaiados em uma prensa hidráulica com rigidez elevada; para tanto, desenvolveu-se uma gaiola de reação em aço 1020 para ensaio dos corpos-de-prova na prensa. A gaiola se compunha de duas peças básicas: uma inferior, para fixação dos corpos-de-prova e uma superior, para acoplagem da célula de carga. A parte inferior da gaiola era formada de uma chapa de aço de $25,4 \mathrm{~mm}$ de espessura, na qual foram soldadas 4 barras de aço de $19 \mathrm{~mm}$ de diâmetro, para união da parte inferior à superior. Na peça inferior também foi realizado um furo de $40 \mathrm{~mm}$ de diâmetro para passagem das varetas de bambu a serem fixadas à garra ativa da prensa hidráulica. A peça superior era constituída de uma chapa de aço de 25,4 mm de espessura, na qual era fixada a peça inferior da gaiola. Ainda na peça superior foram soldadas 4 barras de aço de $10 \mathrm{~mm}$ de diâmetro, que atravessavam todo o bloco reativo da máquina de ensaio. Acima do bloco reativo fixaram-se, às quatro barras, duas chapas menores de $12,5 \mathrm{~mm}$ de espessura, entre as quais foi disposta uma célula de carga com capacidade de força de $100 \mathrm{kN}$. Entre a chapa inferior da gaiola e a base do cilindro de concreto, foi disposta uma placa de neoprene para uma distribuição melhor das forças. Um medidor de deslocamento mecânico com sensibilidade de $0,01 \mathrm{~mm}$ e curso de $50 \mathrm{~mm}$, foi utilizado para medir os deslocamentos relativos entre o concreto e o bambu. $\mathrm{O}$ medidor de deslocamento foi fixado ao bloco cilíndrico de concreto, por meio de uma base magnética e de presilhas de aço. Cuidados foram tomados para evitar qualquer contato entre o medidor de deslocamento e a gaiola metálica. Este procedimento teve como objetivo evitar que deslocamentos parasitas, oriundos da acomodação da gaiola e do cilindro de concreto, interferissem nas leituras dos deslocamentos. $\mathrm{Na}$ Figura 3 apresentam-se detalhes do sistema de reação desenvolvido para o ensaio de arrancamento.

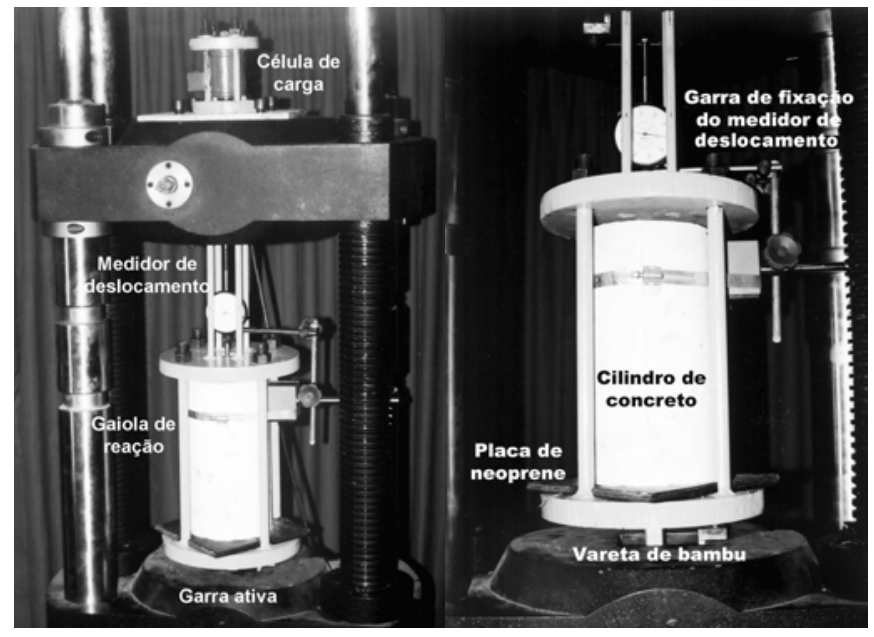

Figura 3. Detalhes do ensaio de arrancamento

A força de arrancamento foi aplicada de modo quase estático, monotonicamente, com controle de força. As leituras dos instrumentos foram realizadas manualmente a cada $0,10 \mathrm{~mm}$ de deslocamento. A duração média de cada ensaio foi da ordem de $10 \mathrm{~min}$, sendo o mesmo concluído quando o deslocamento relativo bambu-concreto atingia $5 \mathrm{~mm}$. Após o ensaio, todos os blocos de concreto foram partidos ao meio por compressão diametral, para análise da superfície de aderência.

\section{RESULTADOS E DISCUSSÃO}

\section{Comportamento geral}

As resistências dos concretos dos corpos-de-prova ficaram próximas das resistências preestabelecidas; em todas as concretagens os concretos apresentaram boa trabalhabilidade, com abatimento no cone de Abrams de $15 \pm 2 \mathrm{~cm}$. Na Tabela 1 apresentaram-se as resistências médias e características dos concretos utilizados no dia dos ensaios de arrancamento.

O mecanismo de ensaio desenvolvido neste trabalho mostrou-se adequado. A gaiola de reação apresentou elevada rigidez para a intensidade de força aplicada nos ensaios. $\mathrm{Na}$ grande maioria dos corpos-de-prova, foi possível conduzir o ensaio até o deslocamento relativo bambu-concreto de $5 \mathrm{~mm}$. Apenas em alguns corpos-de-prova com dois pinos de aço as varetas de bambu romperam a tração, quando o deslocamento relativo se aproximava daquele valor. Apesar do fato, esses ensaios não foram comprometidos, uma vez que os deslocamentos relativos já eram bem superiores ao valor utilizado para o cálculo das tensões de aderência, 0,1 mm. Nesses ensaios, as curvas tensão de aderência versus deslocamento relativo bambu-concreto foram extrapoladas por meio de polinômios obtidos por análise de regressão sobre os dados dos ensaios.

O comportamento dos 6 corpos-de-prova utilizados na avaliação da eficiência da técnica aplicada para anular a aderência bambu-concreto nas extremidades das varetas, foi semelhante. Não se constatou influência da resistência do concreto nesses corpos-de-prova e a tensão de aderência 
média calculada para o deslocamento de $0,1 \mathrm{~mm}$ foi de apenas $0,07 \mathrm{MPa}$. Observa-se que este valor é praticamente desprezível.

Nas Figuras 4A e 4B apresentam-se as curvas tensão de aderência versus deslocamento relativo bambu-concreto para os diversos corpos-de-prova da $1^{\text {a }}$ fase da investigação. Ainda na Figura 4B, tem-se as curvas tensão de aderência versus deslocamento relativo aço-concreto. Observa-se, em todos os corpos-de-prova de bambu, boa uniformidade no comportamento entre os diagramas das 10 réplicas. $\mathrm{O}$ comportamento dos diagramas de tensão de aderência versus deslocamento do bambu-concreto, é semelhante à curva de aderência do aço liso. Inicialmente, nota-se um trecho vertical, que se caracteriza $\mathrm{p}$ ela parcela da aderência por adesão (estágio 1); em seguida, evidencia-se pequeno pico de tensão e o início da aderência por atrito (estágio 2). A partir desse ponto, verifica-se pequena queda da tensão de aderência, tornando-se constante até o deslocamento de $5 \mathrm{~mm}$; já nos diagramas das barras de aço nota-se, após os estágios 1 e 2, um aumento significativo da tensão de aderência aço-concreto, devido à aderência mecânica.

Após ensaio, todos os corpos-de-prova tiveram o bloco cilíndrico de concreto partido ao meio, por compressão diametral. Na Figura 5 apresentam-se fotografias das superfícies das varetas de bambu e de aço, após ensaio da $1^{\mathrm{a}}$ fase da investigação. Nas fotografias das varetas constatam-se regiões de pasta de concreto aderida ao bambu, caracterizando cisalhamento da pasta da região de interface bambu-concreto; o mesmo é observado para a vareta de aço; contudo, constatou-se que, ao toque, a aderência desta pasta com o aço era maior do que nas varetas de bambu. Em alguns corpos-de-prova observou-se que fibras de bambu cisalharam e se separaram das varetas, ficando aderidas à massa de concreto.

Nas Figuras 6A e 6B apresentam-se as curvas tensão de aderência versus deslocamento relativo bambu-concreto, para os diversos corpos-de-prova da $2^{\mathrm{a}}$ fase. Novamente, observa-se boa uniformidade no comportamento entre os diagramas das 10 réplicas. Nos corpos-de-prova 1PACA, após os estágios 1 e 2, notou-se que o aumento da tensão de aderência devido à aderência mecânica, não foi significativo. Analisando-se as varetas de bambu após ensaio (Figura 7), vêse que este comportamento foi provocado por causa do esmagamento da parede do bambu em contado com o pino de aço. Deste modo e apesar do pino de aço criar elevada aderência mecânica, esta não consegue se desenvolver efetivamente, uma vez que a resistência ao esmagamento da parede do furo do bambu é pequena.

Nos corpos-de-prova 1PBCA, a parcela de aderência mecânica só foi evidenciada para deslocamentos superiores a $1 \mathrm{~mm}$ e, mesmo assim, o aumento da tensão não foi significativo. Nesses corpos-de-prova observou-se tanto o esmagamento do pino de bambu quanto o da parede do furo das varetas (Figura 7). Analisando-se os diagramas dos corposde-prova 1PASA e 1PBSA, tem-se que os pinos são responsáveis por uma parcela da aderência por adesão e atrito. $\mathrm{O}$ comportamento geral desses corpos-de-prova foi semelhante ao daqueles com aderência, tanto na forma dos diagramas como nos modos de colapso; contudo, nota-se queda da tensão máxima para o deslocamento nulo. Ao se comparar os diagramas 2PACA com os 1PACA, verifica-se aumento de $60 \%$ na tensão para o ponto de deslocamento nulo, mantendo-se este comportamento até o deslocamento de $5 \mathrm{~mm}$. Para os diagramas 2PBCA e 1PBCA, o comportamento foi similar ao daqueles com pinos de aço, mas o aumento relativo da tensão foi de aproximadamente $43 \%$.

\section{Tensão de aderência}

Na Tabela 3 são apresentadas as tensões de aderência para cada tipo de corpo-de-prova ensaiado, com as respectivas tensões médias e desvios-padrão. Objetivando-se analisar a influência das dimensões da seção transversal das varetas de bambu (fator $\mathrm{X}_{1}$ ) e da resistência à compressão do concreto (fator $\mathrm{X}_{2}$ ), realizou-se uma análise de variância sobre os valores das tensões de aderência apresentados na Tabela $3 \mathrm{a}$. Os graus de significância do efeito de cada fator foram testados para níveis de confiabilidade de 95 e 99\%, usando-se o teste F. Na Tabela 4, apresentam-se os resultados da análise de variância realizada. Com base nesses resultados, conclui-se que a influência das dimensões da seção transversal das varetas de bambu é não significativa para um nível de confiabilidade de 99\%; já a resistência do concreto mostrouse significante para um nível de confiabilidade de $99 \%$. Notase que a interação entre os dois fatores estudados não apresenta significância para o mesmo nível de confiabilidade. Visando à obtenção de uma equação de correlação entre a resistência do concreto e a tensão média de aderência bambu-concreto, realizou-se uma análise de regressão múltipla não-linear com os dados apresentados na Tabela $3 \mathrm{~A}$. A equação obtida apresentou coeficiente de correlação $\left(\mathrm{R}^{2}\right)$ de $73 \%$, e é dada pela Eq. 4:

$$
\tau_{\mathrm{bm}}=0,026977 \cdot \mathrm{f}_{\mathrm{ck}}+1,420459
$$

na qual $\mathrm{f}_{\text {ck }}$ é a resistência à compressão característica do concreto em MPa. Observa-se que a tensão de aderência bambu-concreto varia linearmente com $\mathrm{f}_{\mathrm{ck}}$.

Na Tabela 3, também, apresentam-se as tensões de aderência para os ensaios da $2^{\mathrm{a}}$ fase da investigação. Comparando-se o valor médio da tensão de aderência dos corposde-prova sem aderência $(0,07 \mathrm{MPa})$ com os resultados das varetas com um pino de aço, um pino de bambu e sem aderência, constata-se que os pinos elevaram a tensão de aderência bambu-concreto, sendo responsáveis por um acréscimo de 0,89 e $0,78 \mathrm{MPa}$, respectivamente; subtraindo-se esses valores dos valores das tensões de aderência média dos corpos-de-prova 1PACA e 1PBCA, obter-se-ão os valores de 0,68 e 0,53 $\mathrm{MPa}$, respectivamente; esses valores de tensões correspondem à parcela da tensão de aderência por adesão mais atrito que foi, em média, de 0,60 MPa e, também, que a diferença entre esses valores para os dois tipos de pino foi pequena, considerando-se os desvios-padrão das amostras.

Finalmente, tendo em vista os corpos-de-prova com varetas de bambu de $2 \mathrm{~cm}$ de largura e resistência do concreto de $25 \mathrm{MPa}$, ensaiados na $1^{\mathrm{a}}$ fase, observa-se que eles 

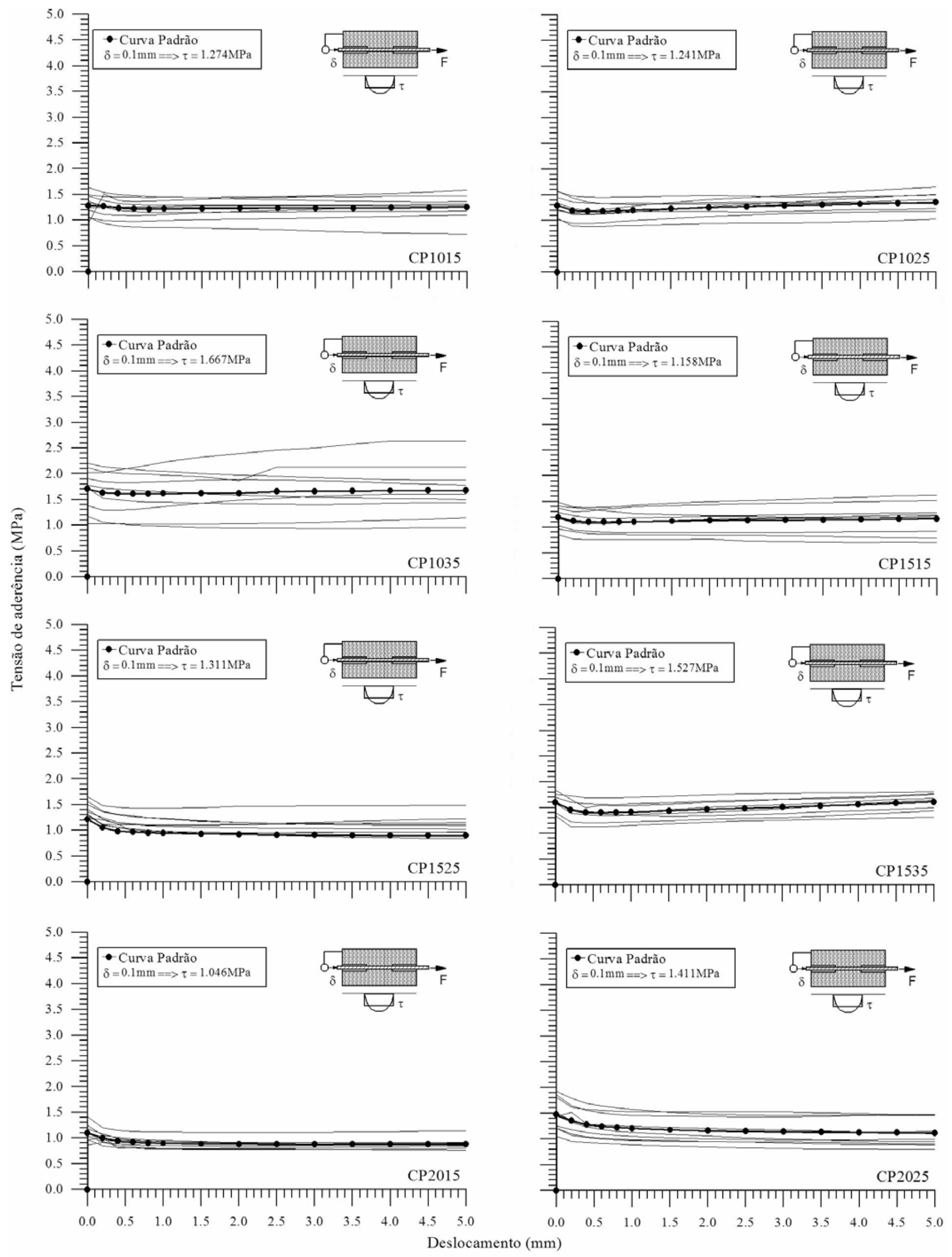

Figura 4. Diagramas tensão de aderência versus deslocamento relativo bambu-concreto para os diversos corpos-de-prova da $1^{\text {a }}$ fase (continua) 

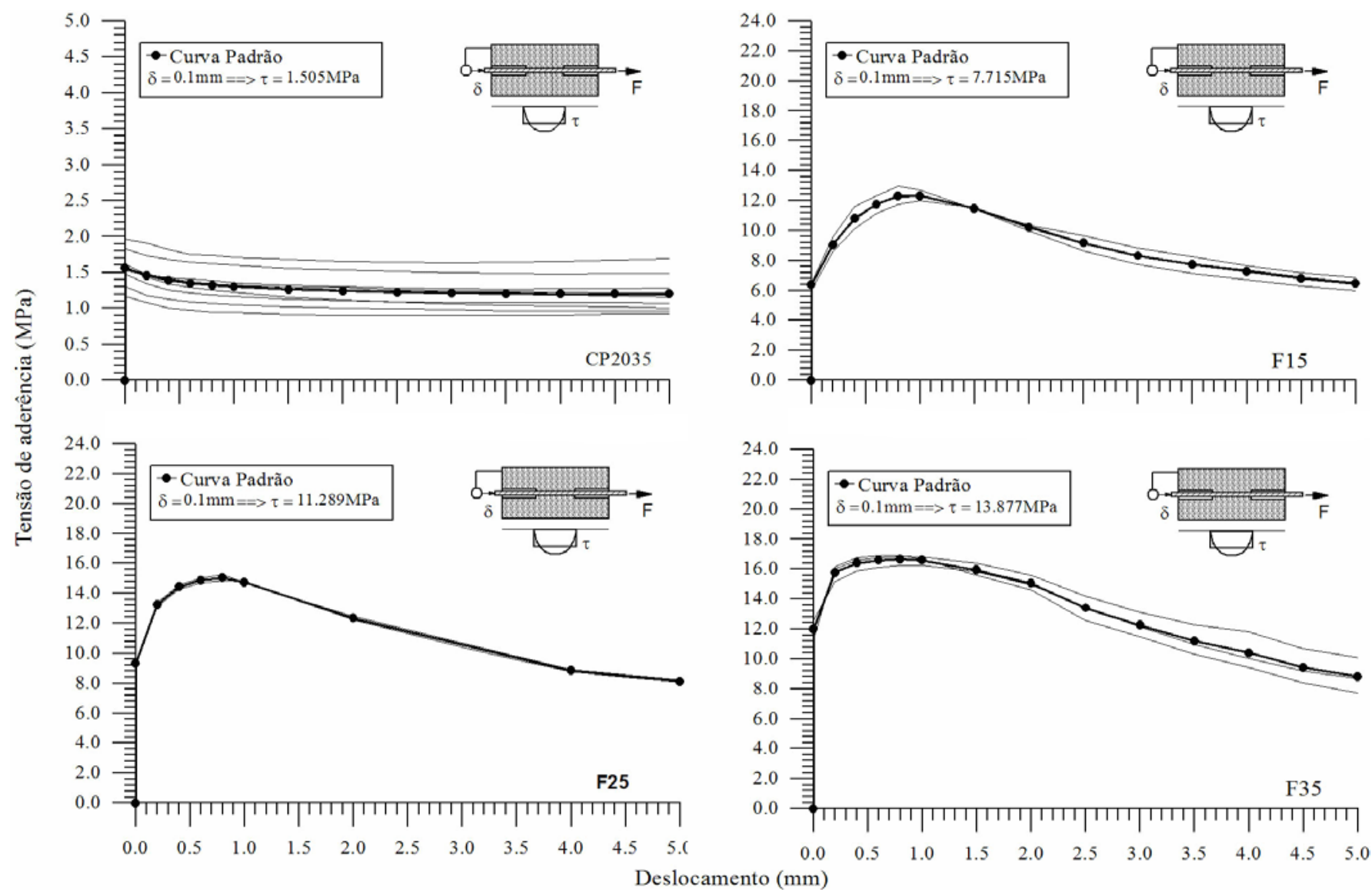

Figura 4. Diagramas tensão de aderência versus deslocamento relativo bambu-concreto para os diversos corpos-de-prova da $1^{\text {a }}$ fase
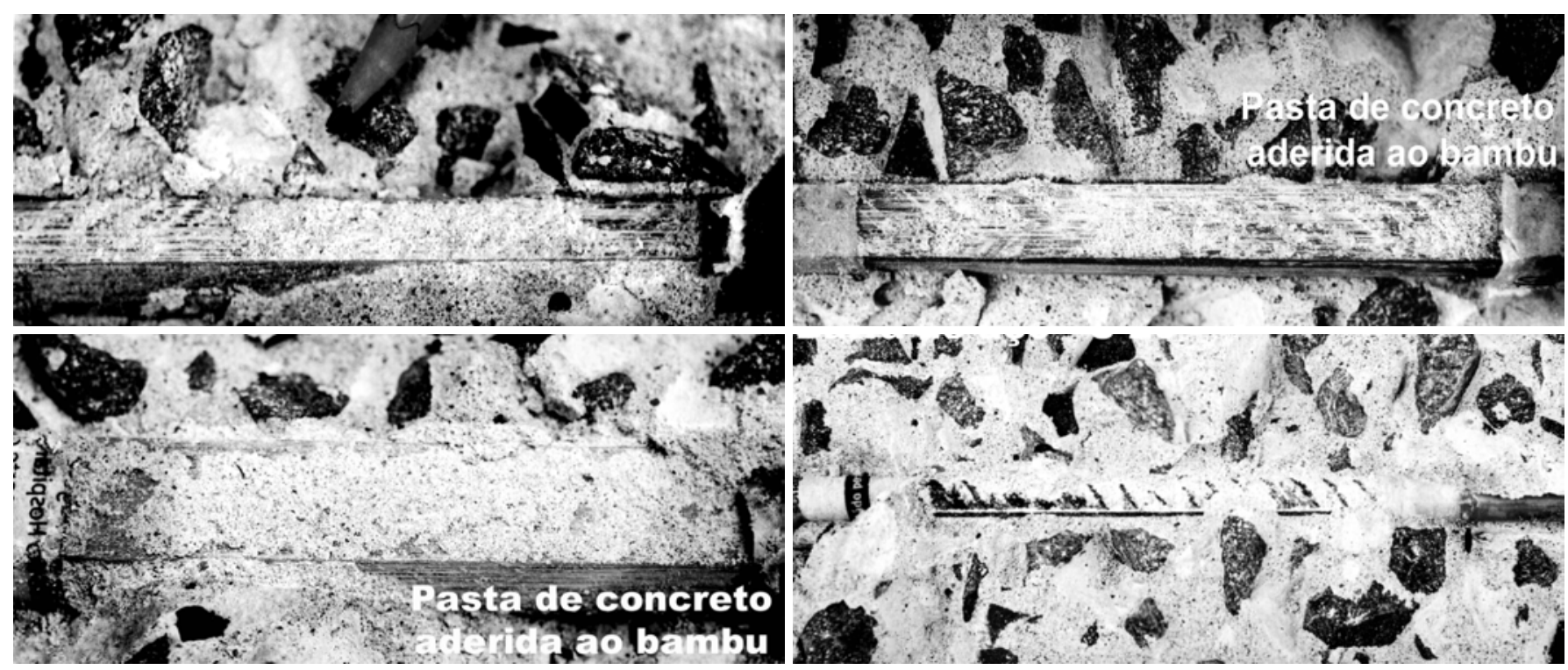

Figura 5. Aparência das varetas de bambu após o teste de arrancamento da $1^{\text {a }}$ fase 

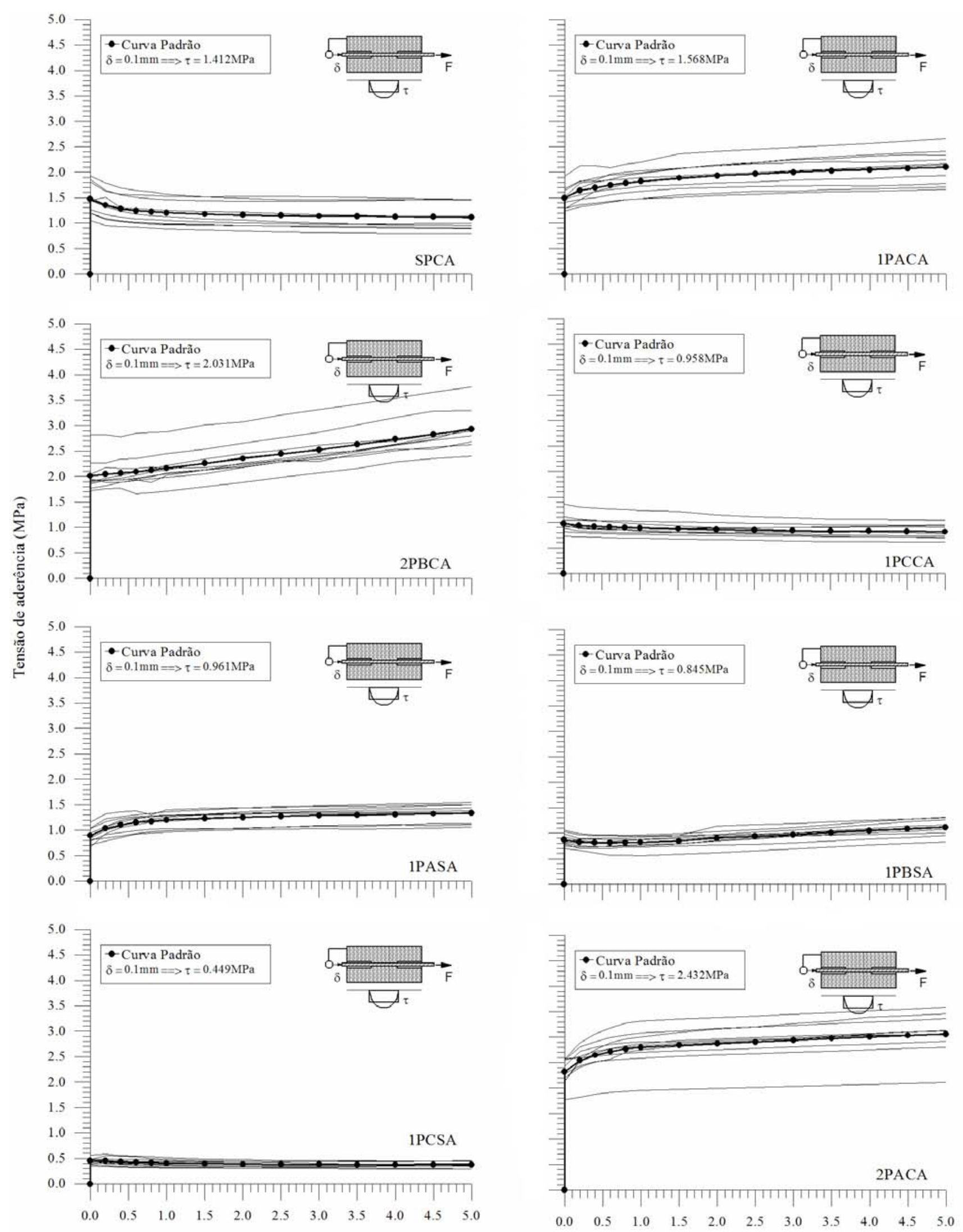

Deslocamento $(\mathrm{mm})$

Figura 6. Diagramas tensão de aderência versus deslocamento relativo bambu-concreto para os diversos corpos-de-prova da $2^{\mathrm{a}}$ fase (continua) 


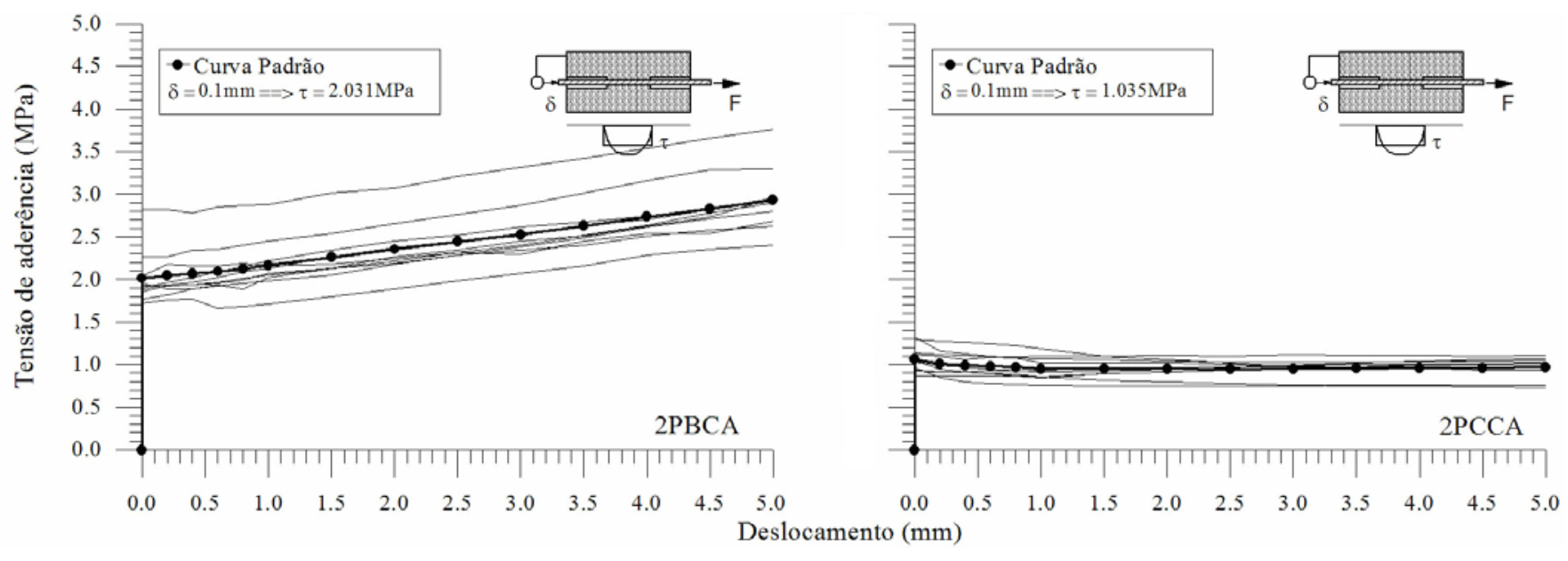

Figura 6. Diagramas tensão de aderência versus deslocamento relativo bambu-concreto para os diversos corpos-de-prova da $2^{\text {a }}$ fase

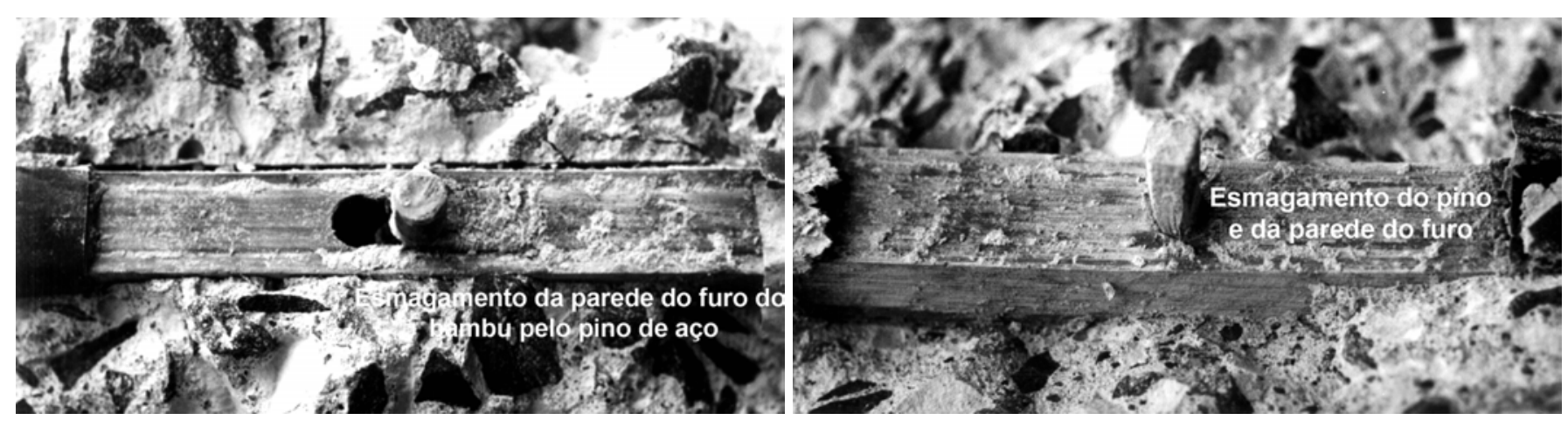

Figura 7. Aparência das varetas de bambu após o teste de arrancamento da $2^{\mathrm{a}}$ fase

Tabela 3. Tensões de aderência dos corpos-de-prova (MPa) obtidos nos ensaios

\begin{tabular}{|c|c|c|c|c|c|c|c|c|c|c|c|}
\hline \multicolumn{12}{|c|}{ Ensaios da $1^{a}$ fase } \\
\hline \multirow{2}{*}{ Tipo } & \multicolumn{10}{|c|}{ Corpos-de-prova } & \multirow{2}{*}{$\tau_{\mathrm{bm}}-\mathrm{s}$} \\
\hline & CP1 & CP2 & CP3 & CP3 & CP5 & CP6 & CP7 & CP8 & CP9 & CP10 & \\
\hline CP1015 & 0,991 & 1,020 & 1,243 & 1,150 & 1,315 & 1,426 & 1,472 & 1,226 & 1,310 & 1,585 & $1,27-0,19$ \\
\hline CP1025 & 1,518 & 0,965 & 1,170 & 0,984 & 1,286 & 1,162 & 1,403 & 1,503 & 1,178 & 1,412 & $1,25-0,19$ \\
\hline CP1035 & 2,082 & 1,116 & 2,020 & 1,625 & 1,873 & 1,340 & 1,029 & 1,750 & 2,176 & 1,642 & $1,66-0,39$ \\
\hline CP1515 & 1,137 & 1,391 & 1,252 & 0,987 & 0,811 & 1,130 & 1,335 & 0,936 & 1,442 & 1,148 & $1,15-0,20$ \\
\hline CP1525 & 1,216 & 1,465 & 1,197 & 1,210 & 1,567 & 1,429 & 1,312 & 1,300 & 1,207 & 1,133 & $1,30-0,14$ \\
\hline CP1535 & 1,517 & 1,650 & 1,237 & 1,750 & 1,490 & 1,516 & 1,313 & 1,747 & 1,489 & 1,612 & $1,53-1,16$ \\
\hline CP2015 & 0,890 & 1,303 & 1,145 & 1,125 & 1,025 & 1,056 & 0,906 & 0,986 & 0,978 & 1,101 & $1,05-0,12$ \\
\hline CP2025 & 1,001 & 1,483 & 1,711 & 1,854 & 1,385 & 1,138 & 1,434 & 1,750 & 1,148 & 1,215 & $1,41-029$ \\
\hline CP2035 & 1,778 & 1,239 & 1,497 & 1,410 & 1,523 & 1,516 & 1,933 & 1,499 & 1,120 & 1,540 & $1,50-0,23$ \\
\hline \multicolumn{12}{|c|}{ Ensaios da $2^{\mathrm{a}}$ fase } \\
\hline \multirow{2}{*}{ Tipo } & \multicolumn{10}{|c|}{ Corpos-de-prova } & \multirow{2}{*}{$\tau_{\mathrm{bm}}-s$} \\
\hline & CP1 & CP2 & CP3 & CP3 & CP5 & CP6 & CP7 & CP8 & CP9 & CP10 & \\
\hline 1PASA & 0,800 & 1,005 & 1,130 & 0,750 & 1,240 & 0,920 & 0,850 & 1,100 & 0,830 & 1,005 & $0,96-0,16$ \\
\hline $1 \mathrm{PBSA}$ & 0,680 & 1,025 & 0,885 & 0,995 & 0,815 & 0,745 & 0,855 & 0,740 & 0,935 & 0,780 & $0,85-0,11$ \\
\hline 1PACA & 1,520 & 1,325 & 1,440 & 1,755 & 1,275 & 1,370 & 1,730 & 2,025 & 1,585 & 1,655 & $1,57-0,23$ \\
\hline $1 \mathrm{PBCA}$ & 1,290 & 1,265 & 1,370 & 1,350 & 1,380 & 1,555 & 1,285 & 1,330 & 1,120 & 1,145 & $1,31-0,12$ \\
\hline 2PACA & 2,590 & 1,795 & 2,350 & 2,685 & 2,590 & 2,735 & 2,335 & 2,310 & 2,360 & 2,575 & $2,43-0,27$ \\
\hline $2 \mathrm{PBCA}$ & 1,913 & 1,740 & 1,920 & 1,935 & 2,820 & 2,265 & 1,793 & 2,107 & 1,890 & 1,920 & $2,03-0,31$ \\
\hline
\end{tabular}


Tabela 4. Análise de variância dos valores da tensão de aderência bambuconcreto

\begin{tabular}{ccccccc}
\hline Variável & SS & $\mathbf{N}$ & $\mathbf{M S}$ & Fator $\left.\mathbf{( F}_{\mathbf{0}}\right)$ & $\mathbf{F}_{0.01, n, 81}-\mathbf{F}_{0.05, n, 81}$ \\
Fatores & & & & & & \\
$X_{1}$ & 0,23187 & 2 & 0,11593 & 0,7942 & 4,913 & 3,122 \\
$X_{2}$ & 4,86510 & 2 & 2,43225 & 16,6636 & 4,913 & 3,122 \\
Interaçōes & & & & & & \\
$X_{1} \times X_{2}$ & 1,36187 & 4 & 0,34047 & 2,3323 & 3,591 & 2,502 \\
Residuo & 11,82437 & 81 & 0,14598 & - & & \\
Total & 18,28320 & 89 & - & - & & \\
\hline
\end{tabular}

Nota: SS é a soma dos quadrados, $N$ é o número de graus de liberdade, MS é a média dos quadrados e $\mathrm{F}_{0.01, n, 81}$ e $\mathrm{F}_{0.05, n, 81}$ são os valores requerido para a significância de $99 \%$ e $95 \%$.

apresentaram tensão média de aderência de 1,41 MPa, ou seja, 135\% superior ao valor da tensão de aderência de adesão mais atrito obtido para os corpos-de-prova com pinos da $2^{\mathrm{a}}$ fase.

Ao contrário do esperado, o efeito de superposição das tensões não ocorreu. Acredita-se que este fato seja proveniente da presença do furo; por outro lado, observa-se que as paredes paralelas às fibras das varetas de bambu apresentam permeabilidade inferior à das paredes transversais, devido ao efeito de capilaridade do sistema vascular do bambu, que neste último caso, se encontra seccionado transversalmente; assim, a absorção da água de amassamento do concreto na região do furo é mais intensa, comprometendo ainda mais a aderência bambu-concreto. Ainda no caso dos corpos-de-prova com pinos de bambu, tal efeito é mais intenso, uma vez que os próprios pinos também absorvem água.

Outro fato que merece menção é que, apesar de cravados sob pressão, os pinos de bambu não apresentavam seção transversal circular uniforme, visto que foram confeccionados manualmente, o que pode ter gerado concentração de tensões na parede do furo e deslocamento de corpo-rígido dos pinos.

Nos corpos-de-prova com dois pinos de aço e naqueles com dois pinos de bambu, verifica-se que a tensão de aderência foi maior que a dos corpos-de-prova sem pinos, em média de 73 e 44\%, respectivamente. Considerando-se ainda a parcela de aderência mecânica gerada por cada pino de aço e de bambu $(0,89$ e $0,78 \mathrm{MPa}$, respectivamente) e a parcela da aderência por adesão mais atrito $(0,68$ e 0,53 $\mathrm{MPa}$, respectivamente), as tensões médias de aderência para os 2PACA e 2PBCA calculada com esses valores, são 2,46 e 2,09 $\mathrm{MPa}$, respectivamente. Nota-se que os referidos valores diferem dos valores das tensões apresentadas na Tabela 3 b de somente 1,23 e $2,96 \%$.

\section{Tensão de aderência de cálculo bambu-concreto}

Seguindo os procedimentos sugeridos pelos códigos normativos para aço-concreto, considerou-se que a tensão de aderência característica entre bambu-concreto segue uma distribuição Normal. Considerando-se, ainda uma probabilidade de apenas 5\% dos valores serem inferiores ao valor característico, tem-se que a tensão característica de aderência bambu-concreto pode ser calculada com base na Eq. 5:

$$
\tau_{\mathrm{bk}}=\tau_{\mathrm{bm}}-\frac{\mathrm{p} \cdot \mathrm{s}}{\sqrt{\mathrm{n}}}
$$

na qual $\tau_{\mathrm{bm}}$ é a tensão de aderência média, s é o desvio-padrão da amostra, n é o número de leituras e p é um coeficiente estatístico que, para o quantil de 5\%, é 1,645. Para se calcular o valor da aderência de cálculo do bambu $\left(\tau_{\mathrm{bd}}\right)$, utilizou-se o coeficiente de segurança sugerido pelo Eurocode (1992), de 2,15 para o aço-concreto.

$\mathrm{Na}$ Tabela 5 apresentam-se os valores característicos e de cálculo da tensão de aderência para o bambu, obtidos dos ensaios experimentais da $1^{\text {a }}$ fase da investigação. Observa-se que as diferenças entre as tensões de aderência de cálculo do bambu e do aço liso, calculadas segundo Eurocode (1992), para concretos com resistência à compressão de $15 \mathrm{MPa}$ é, em média, de apenas 10\%; entretanto, elevando-se a resistência do concreto para $35 \mathrm{MPa}$, esta diferença aumenta para $30 \%$.

A Tabela 5, também, apresenta os valores característicos e de cálculo da tensão de aderência para o bambu com pinos. A cravação de um pino de aço e de bambu praticamente não gerou aumentos significativos na tensão de aderência de cálculo; contudo, observa-se que, quando 2 pinos de aço e de bambu são introduzidos, ocorre uma elevação da ordem de 80 e $50 \%$ na tensão de aderência de cálculo, respectivamente, e que são obtidos valores superiores aos das barras de aço liso, mas esses valores ainda são inferiores ao valor dos aços nervurados.

Tem-se ainda na Tabela 5, os valores característicos e de cálculo da tensão de aderência para as barras de aço nervuradas obtidas experimentalmente; observa-se que esses valores foram, em média, 206\% superiores àquelas calculadas segundo o Eurocode (1992). Verifica-se ainda que a

Tabela 5. Tensões de aderência experimentais e teóricas (MPa)

\begin{tabular}{|c|c|c|c|c|c|}
\hline Tipo & $\tau_{\mathrm{bm}}$ & $\tau_{\mathrm{bk}}$ & $\tau_{\mathrm{bd}}$ & $\begin{array}{l}\text { Tensão de aderência para a } \\
\text { barra de aço lisa }\left(\tau_{\mathrm{ad}}\right)[16]\end{array}$ & $\tau_{\mathrm{bd}} / \tau_{\mathrm{ad}}$ \\
\hline \multicolumn{6}{|c|}{ Varetas sem pino - fase $1^{a}$} \\
\hline CP1015 & 1,27 & 1,17 & 0,54 & 0,55 & 0,99 \\
\hline CP1025 & 1,25 & 1,15 & 0,53 & 0,74 & 0,72 \\
\hline CP1035 & 1,66 & 1,45 & 0,67 & 0,94 & 0,71 \\
\hline CP1515 & 1,15 & 1,05 & 0,48 & 0,55 & 0,88 \\
\hline CP1525 & 1,30 & 1,23 & 0,57 & 0,74 & 0,76 \\
\hline CP1535 & 1,53 & 1,44 & 0,67 & 0,94 & 0,71 \\
\hline CP2015 & 1,05 & 0,98 & 0,45 & 0,55 & 0,83 \\
\hline CP2025 & 1,41 & 1,26 & 0,58 & 0,74 & 0,78 \\
\hline CP2035 & 1,50 & 1,38 & 0,64 & 0,94 & 0,68 \\
\hline \multicolumn{6}{|c|}{ Varetas com pino - fase $1^{\text {a }}$ * } \\
\hline 1PACA & 1,57 & 1,45 & 0,67 & \multirow{6}{*}{1,63} & 0,80 \\
\hline $1 \mathrm{PBCA}$ & 1,31 & 1,25 & 0,58 & & 0,69 \\
\hline 1PASA & 0,96 & 0,88 & 0,41 & & 0,49 \\
\hline 1PBSA & 0,85 & 0,79 & 0,37 & & 0,44 \\
\hline 2PACA & 2,43 & 2,29 & 1,06 & & 1,26 \\
\hline $2 \mathrm{PBCA}$ & 2,03 & 1,88 & 0,88 & & 1,05 \\
\hline \multicolumn{6}{|c|}{ Barras de aço * } \\
\hline F15 & 7,71 & 7,16 & 3,33 & 1,07 & 3,09 \\
\hline F25 & 11,28 & 11,05 & 5,14 & 1,60 & 3,20 \\
\hline F35 & 13,87 & 13,69 & 6,36 & 2,21 & 2,87 \\
\hline
\end{tabular}


resistência do concreto não apresenta influência significativa sobre a relação entre as resistências de aderência de cálculo teórica e experimental, sendo esta variação de apenas 3,9\% em relação ao valor médio.

\section{CONCLUSÕES}

1. A gaiola de reação desenvolvida apresentou desempenho satisfatório e a metodologia utilizada nos ensaios mostrou-se adequada, não havendo interferência de deslocamentos parasitas.

2. O comportamento do diagrama tensão de aderência versus deslocamento relativo bambu-concreto é semelhante ao diagrama do aço liso-concreto.

3. A análise de variância mostrou que as dimensões da seção transversal das varetas de bambu não têm influência significativa na tensão de aderência bambu-concreto, porém se verificou que, ao se elevar a resistência à compressão do concreto, eleva-se também a tensão de aderência bambu-concreto.

4. A variação da tensão de aderência bambu-concreto em relação à resistência à compressão do concreto, é linear.

5. Em média geral, a tensão de aderência de cálculo entre o bambu e o concreto foi apenas $20 \%$ inferior à tensão de aderência entre o aço liso e o concreto.

6. Observou-se, para os corpos-de-prova com pinos, que o efeito da superposição das parcelas referentes à tensão de aderência mecânica gerada pelos pinos e à tensão de aderência por adesão mais atrito, gerada pela superfície das varetas de bambu, não é válido.

7. A cravação de dois pinos de aço ou dois pinos de bambu nas varetas elevou a tensão de aderência em 80 e 50\%, respectivamente. Os valores da tensão de aderência de cálculo para esses corpos-de-prova foram superiores aos valores obtidos para o aço liso, em 26 e 5\%.

\section{AGRADECIMENTOS}

Os autores são gratos ao Zoológico Municipal de Cascavel e à Camargo Correa S.A., pela doação dos materiais utilizados neste projeto.

\section{LITERATURA CITADA}

ABNT. NBR NM 52 - Agregado miúdo - Determinação de massa específica e massa específica aparente. Rio de Janeiro:ABNT, 1987, 7p.

ABNT. NBR 5739 - Ensaio de compressão de corpos-de-prova cilíndricos de concreto: método de ensaio. Rio de Janeiro:ABNT, 1994, 7p.

ABNT. NBR NM 248 - Agregados: Determinação da composição granulométrica. Rio de Janeiro:ABNT, 2003, 7p.

ABNT. NBR NM 53 - Agregado graúdo - determinação de massa específica, massa específica aparente e absorção de água. Rio de Janeiro:ABNT, 2003, 7p.
Beraldo, A. L. Bambucreto - o uso do bambu como reforço do concreto. In: Congresso Brasileiro de Engenharia Agrícola, 16, 1987, Jundiaí. Anais... Jundiaí: SBEA, v.2, 1987, p.521-530.

Da Rosa, S. P. A. P. Análise teórica e experimental de colunas de concreto armado com bambu. Rio de Janeiro: PUC, 2002. 135p. Dissertação Mestrado

Eurocode. Design of concrete structures: Part 1: General rules and rules for buildings. London, 1992, 252p.

Ferrão, A. M; Freire, W. J. Aderência entre bambu e concreto: teste de arrancamento com taliscas de Bambusa tuldoides. In: Encontro Brasileiro em Madeiras e em Estruturas de Madeira, 5, 1995, Belo Horizonte. Anais... Belo Horizonte: EBRAMEM, 1995,v.2, p.389-398.

FIB. Structural concrete - Textbook on behavior, design and performance. Updated knowledge of the CEB/FIP Model Code 1990. Comité Euro International du Béton, London, v.1, 1999. 244p.

Geymayer, H. G.; Cox, F. B. Bamboo reinforced concrete. Journal of the American Concrete Institute, Farmington Hills, v.67, n.10, p.841-846, 1970.

Ghavami, K. Ultimate load behavior of bamboo-reinforced lightweight concrete beams. Cement and Concrete Composites, London, v.17, n.4, p.259-351, 1995.

Ghavami, K; Hombeck, R. V. Mechanical properties and waterrepellent treatment of bamboo. In: Latin American Symposium Rational Organization of Building Applied to Low Cost Housing. 1981, São Paulo. Proceedings... São Paulo: IPT/CIB, 1981. v.1, p.49-55.

Helene, P.; Terzian, P. Manual de dosagem e controle do concreto. São Paulo: PINI, 1995, 349p.

Kurian, N. P.; Kalam, A. K. A. Bamboo reinforced soil-cement for rural use. Indian Concrete Journal, New Delhi, n.51, p.382-389, 1977.

Leonhardt, F. Construções de concreto - Princípios básicos do dimensionamento de estruturas de concreto armado. Rio de Janeiro: Interciência, v.1, 1977, 305p.

Lima Jr., H. C.; Xavier, A. C.; Barbosa, N. P.; Toledo Filho, R. D. Aderência bambu-concreto. In: Congresso de Engenharia Civil da Universidade Federal de Juiz de Fora, 2, 1996, Anais... Juiz de Fora: UFJF, 1996, v.1, p.312-323.

Lima Jr., H. C.; Dalcanal, P. R.; Willrich, F. L.; Barbosa, N. P. Características mecânicas do bambu Dendrocalamus giganteus: análise teórica e experimental. In: Barbosa, N. P.; Swamy, R. N.; Lynsdale, C. (ed.). Sustainable construction into the next millennium: environmentally friendly and innovative cement based materials. João Pessoa: Federal University of Paraiba and The University of Sheffield, 2000. p.394-406.

Lopes, W. G. R.; Freire, W. J.; Ferreira, G. C. S. Ensaios de arrancamento e de empuxamento aplicados a taliscas de bambu. Revista Brasileira de Engenharia Agrícola e Ambiental, Campina Grande, v.6, n.3, p.504-510, 2002.

Macgregor, J. G. Reinforced concrete, mechanics and design. New York: Prentice Hall, 1997, 939p.

Montgomery, D. C. Design and analysis of experiments. New York: John Wiley \& Sons, 1984, 704p.

Park, R.; Paulay, T. Reinforced concrete structures. New York: John Wiley \& Sons, 1975, 769p.

RILEM-FIP-CEB. Bond test for reinforcing steel -2 . Pull-Out test. Matériaux et Constructions, Paris, v.6, n.32, p.102-105, 1973. 